\title{
Urban and Rural School Physical Education Development Status Research Under the Horizon of China Dream
}

\author{
Jin Zhang ${ }^{1,}$, Zhaojun Sun $^{2}$ and Houya Zhang ${ }^{2}$ \\ ${ }^{1}$ School of Foreign Language Studies, Shandong Jiaotong University, Jinan 250032, Shandong, China; ${ }^{2}$ Shandong \\ Police College, Jinan 250014, Shandong, China
}

\begin{abstract}
Sports has various functions on students' education, it contains profound connotations and huge potentials. Sports course core problem lies in school's physical education; school education results directly affect contemporary youth physical quality and value orientation. For contemporary physical education course, it has bodybuilding, education, entertainment and other functions, but as sports most basic function, it should be inheritance of Chinese excellent sports culture, through transmitting sports cultural achievements to flowers the future of motherland with physical education course, developing students' practical ability and meeting students' body and mind experiences in entertainment and bodybuilding, and then let students to develop in all-around way. The paper carries out comparative analysis of cities and towns as well as villages' teaching conditions targeted at school physical education situation under the horizon of China dream, in towns and villages' primary schools' sports practice course larger frequency are respectively $72.29 \%, 55.42 \%$ and $45.78 \%$. These proportions are obvious higher than that in cities. In junior high schools' sports practice course, rural proportions are obvious more than cities' junior high school physical education course sports activity practice course, but strength quality and speed quality are correspondingly increasing, but compare to cities, there are still some shortage. As senior high school physical education course, villages and towns' sports practice course proportions are nearly the same as that in cities.
\end{abstract}

Keywords: China dream, comparative analysis, development status, physical education.

\section{INTRODUCTION}

China dream, its essence is rejuvenation of a nation, people happiness, realization of national prosperity and strength, and realization of the great rejuvenation of China [1]. School as motherland future talents fostering place, and meanwhile it also is the subject of Chinese fine tradition cultural inheritance foundation and cultural innovation development, which undertakes sacred mission in China dream realization process [2].

In China, physical education course as an important part in contemporary education, it assists exercises, strengthens physique through physical activity and some equipments, teachers pass on exercises basic knowledge and skills in school and then cultivate modern youth morality and willpower, which is a key link in fostering qualified future successor that develop morality, intelligence, physique, aesthetics and labor in all-around way, since China was founded for 65 years, no matter in the period of socialist construction, physical education always is an important part in Chinese basic education [3]. As Table 1 physical education guiding thoughts changes after the foundation of the country [4].

In school, physical education plays multiple roles in students' education; it contains profound connotations and huge potentials. Physical education course core problem lies in school physical education, school education results directly affect contemporary youth physical quality and value orientation. For contemporary physical education course, it has bodybuilding, education, entertainment and others functions, but as sports most basic function, it should be inheritance of Chinese excellent sports culture, through transmitting sports cultural achievements to flowers the future of motherland with physical education course, developing students' practical ability and meeting students' body and mind experiences in entertainment and bodybuilding, and then let students to develop in all-around way. Chinese long historic, plentiful contents sports culture also lets Chinese physical education course to be colorful, with physical education culture constantly progress and international exchanges, school physical education course constantly injects into new connotation [5].

\section{URBAN AND RURAL SCHOOL PHYSICAL EDU- CATION COMPARISON}

Comparative analysis method can also be called as "contrastive analysis", it is a kind of method that makes comparison of objective existed things, analyzes them, achieves recognition of things essence and rules and then makes correct evaluations on them.

In comparative analysis, in general, it makes comparative analysis of two connected things indicators, exhibits and explains from quantity that researched things scale, levels 
Table 1. Physical education guiding thoughts changes after the foundation of the country.

\begin{tabular}{|c|c|c|c|}
\hline Development Stage & Time & Course Guiding Thoughts & School Physical Education Thoughts \\
\hline \hline $\begin{array}{c}\text { Introduction and } \\
\text { transformation }\end{array}$ & $1949-1956$ & $\begin{array}{c}\text { Enhance health, strengthen physique to provide qualified talents } \\
\text { reserve for national defense construction and production construc- } \\
\text { tion, as well as focusing on "three-bases" imparting thoughts }\end{array}$ & $\begin{array}{c}\text { Physique education, sports skill } \\
\text { education, economic physical education }\end{array}$ \\
\hline $\begin{array}{c}\text { Change and } \\
\text { development }\end{array}$ & $1957-1965$ & Regard strengthening student physique as main ideas & $\begin{array}{c}\text { System education, economic physical } \\
\text { education }\end{array}$ \\
\hline $\begin{array}{c}\text { Ten years frustration } \\
\text { Recovery and } \\
\text { adjustment }\end{array}$ & $1966-1976$ & Labor, military sports education thoughts and anarchic thoughts & $\begin{array}{c}\text { Theory of physical education useless, } \\
\text { use military to replace physical education }\end{array}$ \\
\hline $\begin{array}{c}\text { Reform and } \\
\text { exploration }\end{array}$ & $1977-1985$ & $\begin{array}{c}\text { Here highlights "three bases" imparting and focuses on } \\
\text { strengthening physique thought }\end{array}$ & $\begin{array}{c}\text { System education, sports skill education, } \\
\text { subject education }\end{array}$ \\
\hline $\begin{array}{c}\text { Deepen reform } \\
\text { (1986-1999 }\end{array}$ & 2000 - now & $\begin{array}{r}\text { Thought that highlights propelling to students' personality } \\
\text { development }\end{array}$ & $\begin{array}{c}\text { Theme education, quality education, } \\
\text { lifelong education, system education }\end{array}$ \\
\hline
\end{tabular}

and speed, as well as each kind of mutual relations whether they have mutual impacts and coordination relations or not. In comparative analysis, select appropriate comparison criterion is very crucial. If selected one is proper, and then it can make correct and objective evaluation; if selected one is improper, its evaluation may get wrong conclusions.

Comparative analysis flow chart is as following Fig. (1).

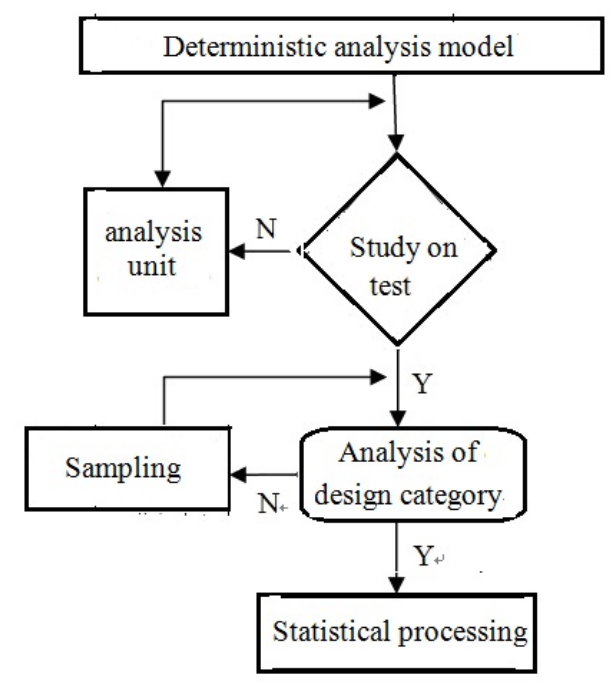

Fig. (1). Comparative analysis flow chart.

For Chinese physical education status under the horizon of China dream, it carries out comparative analysis from urban and rural primary school, junior high school, and senior high school physical education course teaching contents.

Physical education course as subordinate conception of teaching course is an important part in current course. As Chinese curriculum reform constantly goes deeper, physical education course is also constantly moving toward normalization, systematization and materialization. For concrete targets of physical education course, it has also gone through long time discussion, scholars respectively designate physical education course from the perspective of pedagogy, sociology, biology, sports science and so on, they have come to terms that suppose physical education course cultivated targets are enhancing physique and impelling health, as well as the demands on mastering basic sports skills.

\subsection{Primary School Physical Education Course Teaching Contents Comparison}

As primary school's physical education course, it should mainly work on fostering students' sports interests and developing students' basic activity capacity, teaching contents also should base on all kinds of activity skills and games, so primary school's physical education course contents mostly equip with sports games, such teaching contents basically conform to the requirement of physical education course in primary school stage. With regard to this, it makes statistics of city primary school sports practice course contents as Table 2 city primary schools' sports practice course teaching.

Corresponding to above data, it draws "black-white bar figure" as Fig. (2).

From above statistical analysis, it is clear frequency of event 1 , walking and jumping, 2 , leaping, 3 , rope skipping in city primary school sports practice course is bigger that is respectively $53 \%, 43 \%$ and $35 \%$.

Then analyze rural primary school sports practice course teaching contents as Table $\mathbf{3}$ rural primary school sports practice course teaching.

Corresponding to above data, it draws "black-white bar figure" as Fig. (3).

From above statistical analysis, it is clear frequency of event 1, game, 2, walking and running, 3, free-hand exercises in rural primary school sports practice course is bigger that is respectively $72.29 \%, 55.42 \%$ and $45.78 \%$. These proportions are obvious higher than that in cities. 
Table 2. City primary school sports practice course teaching contents situation.

\begin{tabular}{|c|c|c|c|c|c|}
\hline Rank & 1 & 2 & 3 & 4 & 5 \\
\hline Event & Walking and jumping & Leaping & Rope skipping & Free-hand exercises & Procession and formation \\
\hline Frequency & 74 & 60 & 50 & 44 & 36 \\
\hline Percentage & $53.24 \%$ & $43.17 \%$ & $35.97 \%$ & $31.65 \%$ & $25.90 \%$ \\
\hline Rank & 6 & 7 & 8 & 9 & 10 \\
\hline Event & Game & Throwing & Football & Endurance quality & Flexibility quality \\
\hline Frequency & 36 & 36 & 31 & 24 & 24 \\
\hline Percentage & $25.90 \%$ & $25.90 \%$ & $22.30 \%$ & $17.27 \%$ & $17.27 \%$ \\
\hline Rank & 11 & 12 & 13 & 14 & 15 \\
\hline Event & Table tennis & Basketball & Strength quality & Volleyball & Speed quality \\
\hline Frequency & 24 & 22 & 22 & 20 & 20 \\
\hline Percentage & $17.27 \%$ & $15.83 \%$ & $15.83 \%$ & $14.39 \%$ & $14.39 \%$ \\
\hline Rank & 16 & 17 & 18 & 19 & 20 \\
\hline Event & Sensitivity quality & Horizontal bar & Martial Arts & Ascending & Techniques \\
\hline Frequency & 20 & 18 & 18 & 18 & 17 \\
\hline Percentage & $14.39 \%$ & $12.95 \%$ & $12.95 \%$ & $12.95 \%$ & $12.23 \%$ \\
\hline
\end{tabular}

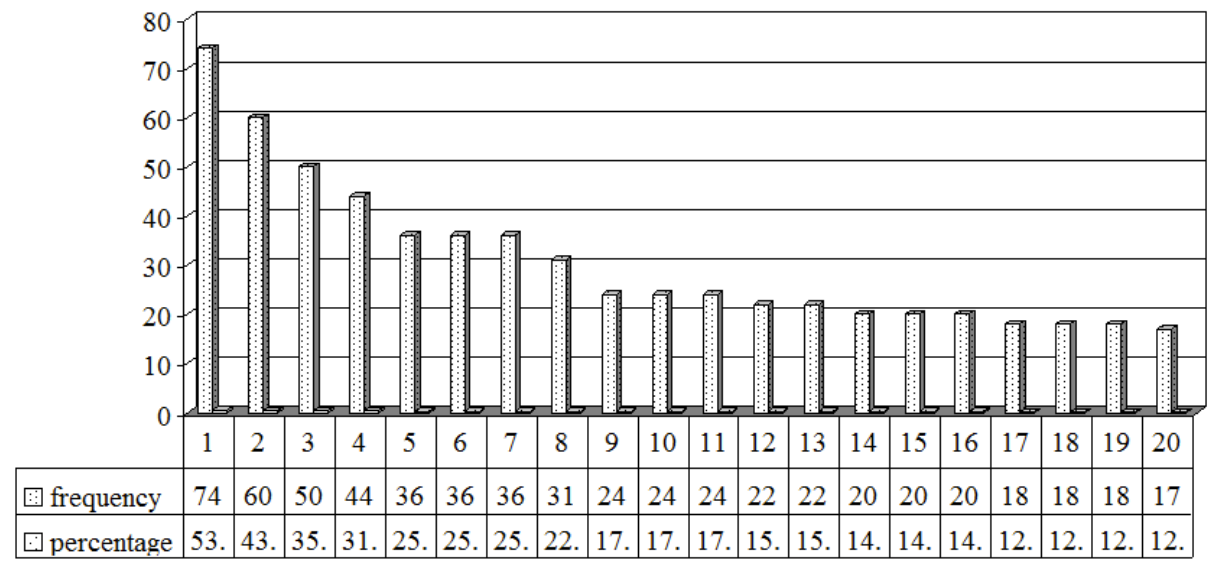

Fig. (2). City primary school sports practice teaching content.

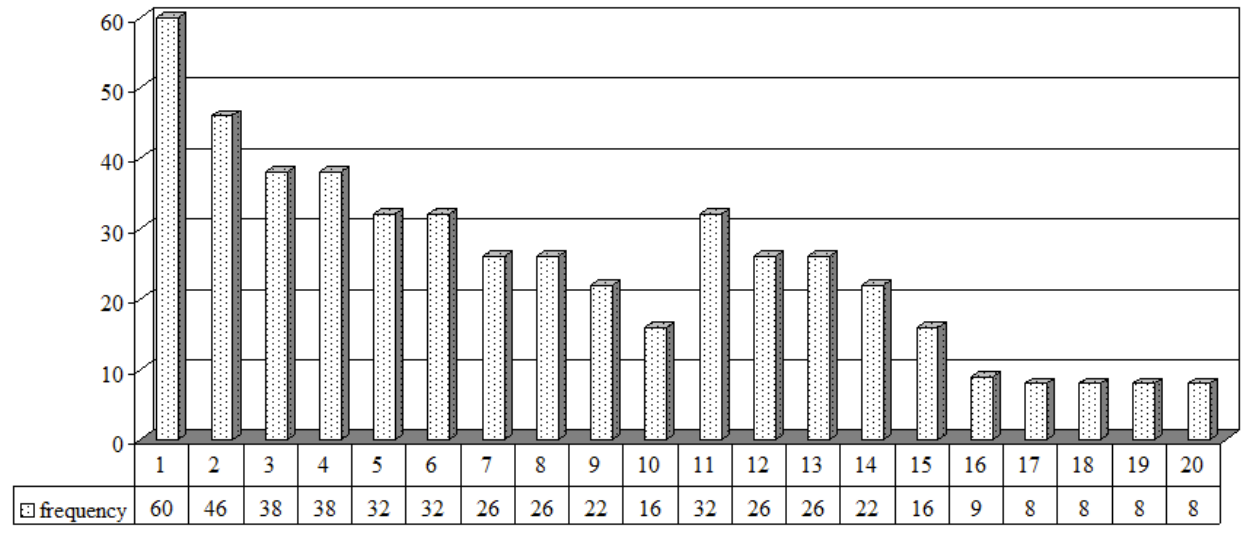

Fig. (3). Township and village elementary school sports teaching practice. 
Table 3. Rural primary school sports practice course teaching.

\begin{tabular}{|c|c|c|c|c|c|}
\hline Event & Game & Walking and running & Free-hand exercises & Basketball & Leaping \\
\hline Frequency & 60 & 46 & 38 & 38 & 32 \\
\hline Percentage & $72.29 \%$ & $55.42 \%$ & 45.78 & $45.78 \%$ & $38.55 \%$ \\
\hline Event & Rope skipping & Throwing & Procession and formation & Table tennis & Martial Arts \\
\hline Frequency & 32 & 26 & 26 & 22 & 16 \\
\hline Percentage & $38.55 \%$ & 31.33 & $31.33 \%$ & $26.51 \%$ & $19.28 \%$ \\
\hline Rank & 11 & 12 & 13 & 14 & 15 \\
\hline Percentage & $19.28 \%$ & $16.87 \%$ & $14.46 \%$ & $12.05 \%$ & $12.05 \%$ \\
\hline Rank & 16 & 17 & 18 & 19 & 20 \\
\hline Event & Football & Badminton & Ascending & Balance & Volleyball \\
\hline Frequency & 9 & 8 & 8 & 8 & 8 \\
\hline Percentage & $10.84 \%$ & $9.64 \%$ & $9.64 \%$ & $9.64 \%$ & $9.64 \%$ \\
\hline
\end{tabular}

Table 4. City' junior high school sports practice course teaching.

\begin{tabular}{|c|c|c|c|c|c|}
\hline Rank & 1 & 2 & 3 & 4 & 5 \\
\hline Event & Walking and running & Throwing & Leaping & Strength quality & Basketball \\
\hline Frequency & 72 & 61 & 59 & 51 & 50 \\
\hline Percentage & $67.92 \%$ & $57.55 \%$ & $55.66 \%$ & $48.11 \%$ & $47.17 \%$ \\
\hline Rank & 6 & 7 & 8 & 9 & 10 \\
\hline Event & Rope skipping & Speed quality & Free-standing exercises & Endurance quality & Procession and formation \\
\hline Frequency & 45 & 44 & 42 & 41 & 40 \\
\hline Percentage & $42.45 \%$ & $41.51 \%$ & $39.62 \%$ & $38.68 \%$ & $37.74 \%$ \\
\hline Rank & 11 & 12 & 13 & 14 & 15 \\
\hline Event & Flexibility quality & Sensitivity quality & Table tennis & Badminton & Game \\
\hline Frequency & 35 & 33 & 30 & 25 & 25 \\
\hline Percentage & $33.02 \%$ & $31.13 \%$ & $28.30 \%$ & $23.58 \%$ & $23.58 \%$ \\
\hline Rank & 16 & 17 & 18 & 19 & 20 \\
\hline Event & Techniques & Martial Arts & Volleyball & Football & Horizontal bar \\
\hline Frequency & 24 & 23 & 22 & 18 & 13 \\
\hline Percentage & $22.64 \%$ & $21.70 \%$ & $20.75 \%$ & $16.98 \%$ & $12.26 \%$ \\
\hline
\end{tabular}




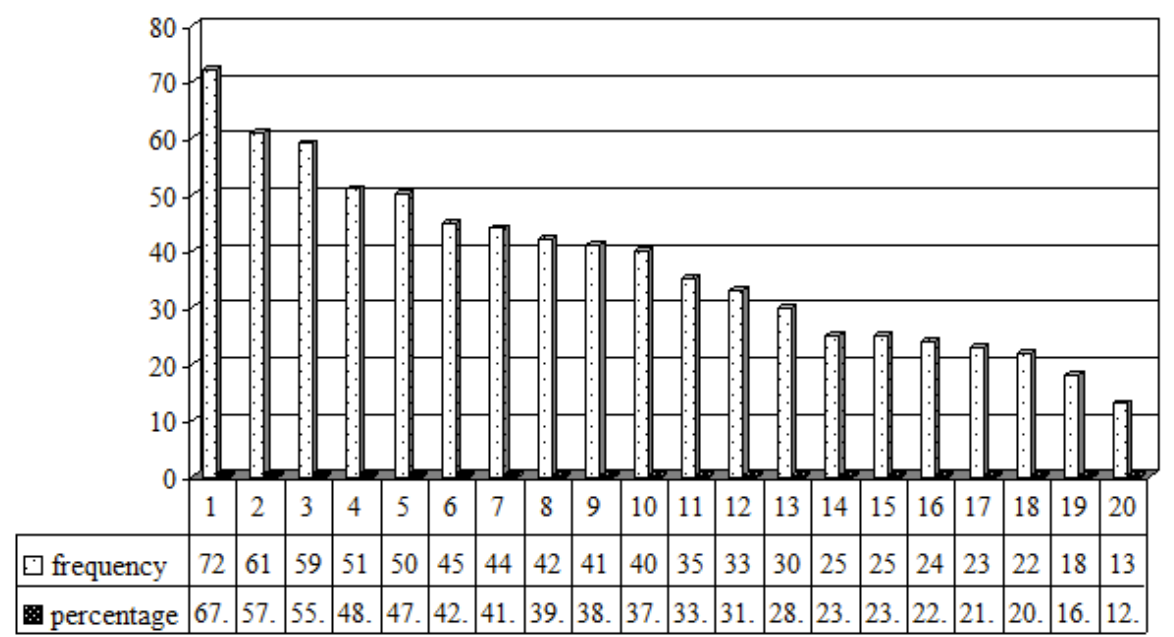

Fig. (4). City middle school sports teaching practice.

Table 5. Rural junior high school sports practice course teaching.

\begin{tabular}{|c|c|c|c|c|c|}
\hline Rank & 1 & 2 & 3 & 4 & 5 \\
\hline Event & Walking and running & Leaping & Throwing & Basketball & Endurance quality \\
\hline Frequency & 91 & 93 & 84 & 69 & 67 \\
\hline Percentage & $72.22 \%$ & $73.81 \%$ & $66.67 \%$ & $54.76 \%$ & $53.17 \%$ \\
\hline Rank & 6 & 7 & 8 & 9 & 10 \\
\hline Event & Speed quality & Free-standing exercises & Procession and formation & Strength quality & Rope skipping \\
\hline Frequency & 62 & 59 & 54 & 54 & 52 \\
\hline Percentage & $49.21 \%$ & $46.83 \%$ & $42.86 \%$ & $42.86 \%$ & $41.27 \%$ \\
\hline Rank & 11 & 12 & 13 & 14 & 15 \\
\hline Event & Game & Table Tennis & Martial Arts & Sensitivity quality & Flexibility quality \\
\hline Frequency & 52 & 38 & 37 & 34 & 30 \\
\hline Percentage & $41.27 \%$ & $30.16 \%$ & $29.37 \%$ & $26.98 \%$ & $23.81 \%$ \\
\hline Rank & 16 & 17 & 18 & 19 & 20 \\
\hline Event & Techniques & Horizontal bar & Football & Badminton & Volleyball \\
\hline Frequency & 30 & 26 & 25 & 23 & 21 \\
\hline Percentage & $23.81 \%$ & $20.63 \%$ & $19.84 \%$ & $18.25 \%$ & $16.67 \%$ \\
\hline
\end{tabular}

\subsection{Junior High School Physical Education Course Teaching Contents Comparison}

As junior high school physical education course, it should also mainly work on fostering students' sports interests and developing students' basic activity capacity, teaching contents also should base on all kinds of activity skills and games, but it needs to properly add some physical education professional knowledge to improve junior high school students' physical health, so junior high school physical education course contents mostly equip with sports games and properly add some professional physical education knowledge, and then such teaching contents can basic conform to the requirements of physical education course in junior high school stage. Here, it makes statistics of city' junior high school sports practice course contents as Table 4 city junior high school sports practice course teaching.

Corresponding to above data, it draws "black-white bar figure" as Fig. (4).

From above statistical analysis, as junior high school physical education course, it also should mainly work on fostering students' sports interests and developing students' basic activity capacity, it is clear that frequency of event 1 , walking and running, 2, throwing, 3, leaping in city junior high school sports practice course is larger that is respectively $76 \%, 57 \%$ and $55 \%$. The proportions are 


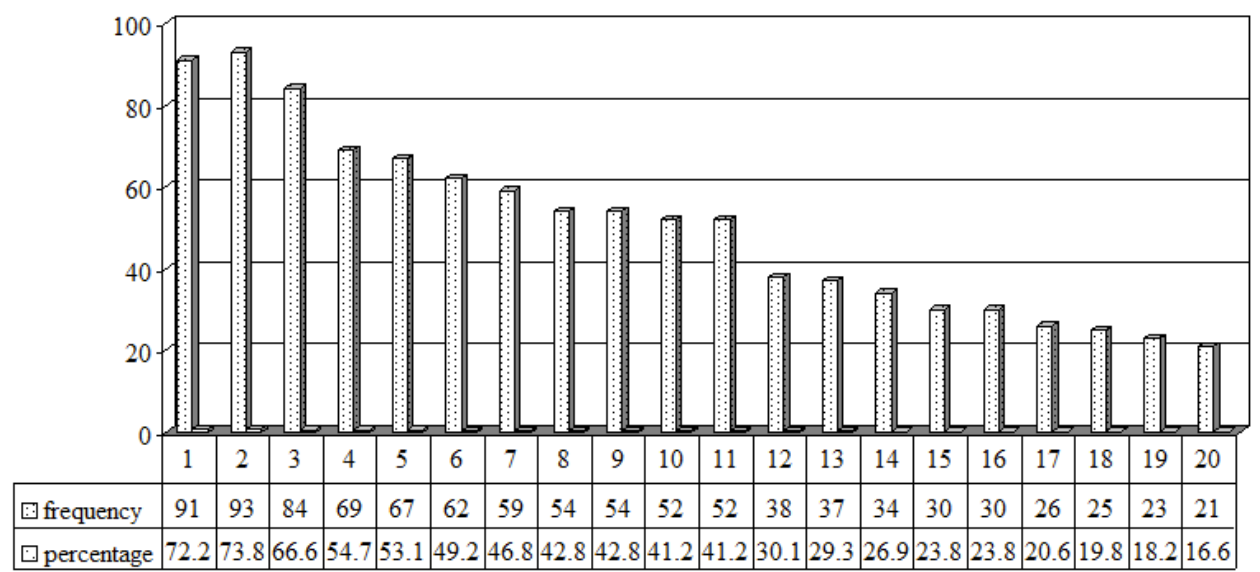

Fig. (5). The villages and towns junior middle school sports teaching practice.

Table 6. City senior high school sports practice course teaching.

\begin{tabular}{|c|c|c|c|c|c|}
\hline Rank & 1 & 2 & 3 & 4 & 5 \\
\hline Event & Basketball & Walking and jumping & Leaping & Football & Volleyball \\
\hline Frequency & 235 & 209 & 168 & 159 & 157 \\
\hline Percentage & $69.32 \%$ & $61.65 \%$ & $49.56 \%$ & $46.90 \%$ & $46.31 \%$ \\
\hline Rank & 6 & 7 & 8 & 9 & 10 \\
\hline Event & Procession and formation & Free-standing exercises & Throwing & Strength quality & Game \\
\hline Frequency & 144 & 141 & 135 & 134 & 132 \\
\hline Percentage & $42.48 \%$ & $41.59 \%$ & $39.82 \%$ & $39.53 \%$ & $38.94 \%$ \\
\hline Rank & 11 & 12 & 13 & 14 & 15 \\
\hline Event & Table tennis & Speed quality & Rope skipping & Sensitivity quality & Endurance quality \\
\hline Frequency & 127 & 126 & 122 & 109 & 106 \\
\hline Percentage & $37.46 \%$ & 37.17 & $35.99 \%$ & $32.15 \%$ & $31.27 \%$ \\
\hline Rank & 16 & 17 & 18 & 19 & 20 \\
\hline Event & Badminton & Martial Arts & Aerobics & Flexibility quality & Techniques \\
\hline Frequency & 106 & 106 & 106 & 88 & 66 \\
\hline Percentage & $31.27 \%$ & $31.27 \%$ & $30.97 \%$ & $25.96 \%$ & $19.47 \%$ \\
\hline
\end{tabular}

obvious less than city primary school sports practice course, but the strength quality and speed quality obvious increase.

Then analyze rural junior high school sports practice course teaching contents as Table 5 rural junior high school sports practice course teaching.

Corresponding to above data, it draws "black-white bar figure" as Fig. (5).

From above statistical analysis, as junior high school physical education course, it also should mainly work on fostering students' sports interests and developing students' basic activity capacity, it is clear that frequency of event 1 , walking and running, 2, leaping, 3, throwing in rural junior high school sports practice course is larger that is respectively $72.2 \%, 73.8 \%$ and $66.6 \%$. The proportions are obvious more than city junior high school sports course's sports activity practice course, but strength quality and speed quality also corresponding increase while still has deficiency with regard to city.

\subsection{Senior High School Physical Education Course Teaching Contents Comparison}

As senior high school physical education course, it should mainly work on fostering students' sports skills and developing students' activity capacity, teaching contents also should base on all kinds of activity skills and corresponding sports event to teach, so senior high school's physical education course contents mostly equip with sports specific events as basketball, football, volleyball and so on, such teaching contents basically conform to requirements of 


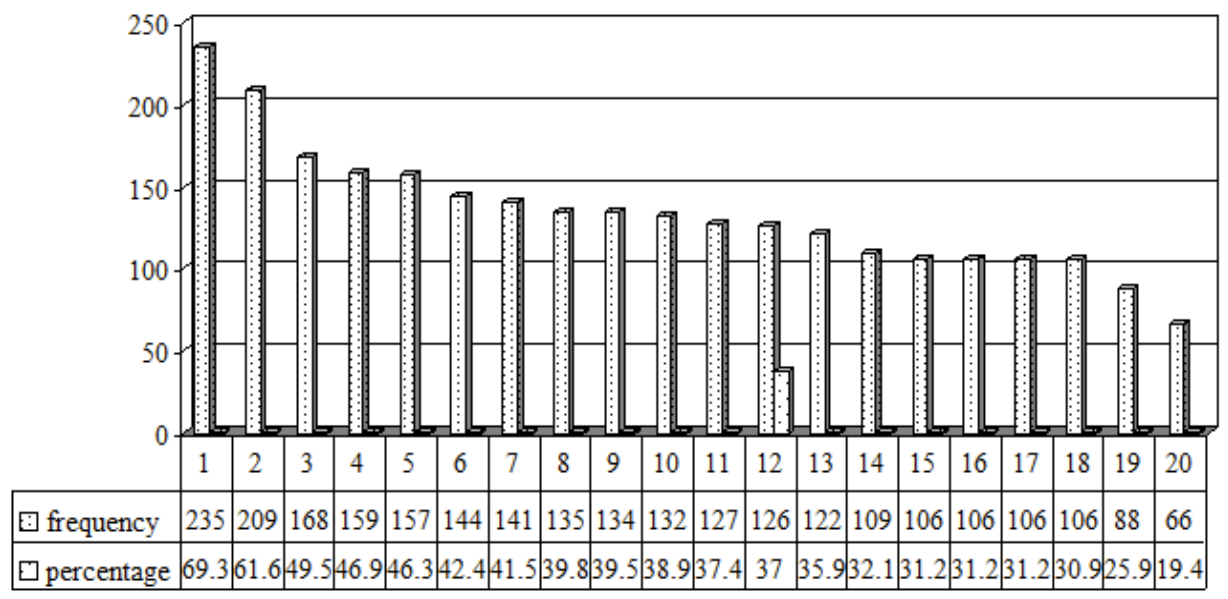

Fig. (6). City high school sports teaching practice.

Table 7. Rural senior high school sports practice course teaching.

\begin{tabular}{|c|c|c|c|c|c|}
\hline Rank & 1 & 2 & 3 & 4 & 5 \\
\hline Event & Basketball & Walking and running & Speed quality & Endurance quality & Throwing \\
\hline Frequency & 43 & 38 & 30 & 29 & 25 \\
\hline Percentage & $66.15 \%$ & $58.46 \%$ & $46.15 \%$ & $44.62 \%$ & $38.46 \%$ \\
\hline Rank & 6 & 7 & 8 & 9 & 10 \\
\hline Event & Free-standing exercises & Strength quality & Leaping & Game & Volleyball \\
\hline Frequency & 25 & 22 & 22 & 18 & 16 \\
\hline Percentage & $38.46 \%$ & $33.85 \%$ & $33.85 \%$ & $27.69 \%$ & $24.62 \%$ \\
\hline Rank & 11 & 12 & 13 & 14 & 15 \\
\hline Event & Flexibility quality & Procession and formation & Rope skipping & Football & Sensitivity quality \\
\hline Frequency & 13 & 13 & 13 & 13 & 10 \\
\hline Percentage & $20 \%$ & $20 \%$ & $20 \%$ & $20 \%$ & $15.38 \%$ \\
\hline Rank & 16 & 17 & 18 & 19 & 20 \\
\hline Event & Badminton & Table tennis & Martial Arts & Techniques & Ascending \\
\hline Frequency & 10 & 6 & 6 & 5 & 5 \\
\hline Percentage & $15.38 \%$ & $9.23 \%$ & $9.23 \%$ & $7.69 \%$ & $7.69 \%$ \\
\hline
\end{tabular}

physical education course in senior high school stage. Here, it makes statistics of city senior high school sports practice course contents as Table 6 city senior high school sports practice course teaching.

Corresponding to above data, it draws "black-white bar figure" as Fig. (6).

From above statistical analysis, it is clear that frequency of event 1, basketball, 2, walking and jumping, 3, leaping in city senior high school sports practice course is larger that is respectively $69.3 \%, 61.6 \%$ and $49.5 \%$.

Then analyze rural senior high school sports practice course teaching contents as Table 7 rural senior high school sports practice course teaching.
Corresponding to above data, it draws "black-white bar figure" as Fig. (7).

From above statistical analysis, it is clear that frequency of event 1, basketball, 2, walking and running, 3, speed quality in rural senior high school sports practice course is larger that is respectively $66.1 \%, 58.4 \%$ and $46.1 \%$. The proportions are nearly the same as that in city.

\section{CONCLUSION}

As an important part in modern education, physical education uses body activity and some equipments to assist exercising, enhancing physique and developing body, teachers impart exercises' basic knowledge and skills in school and 


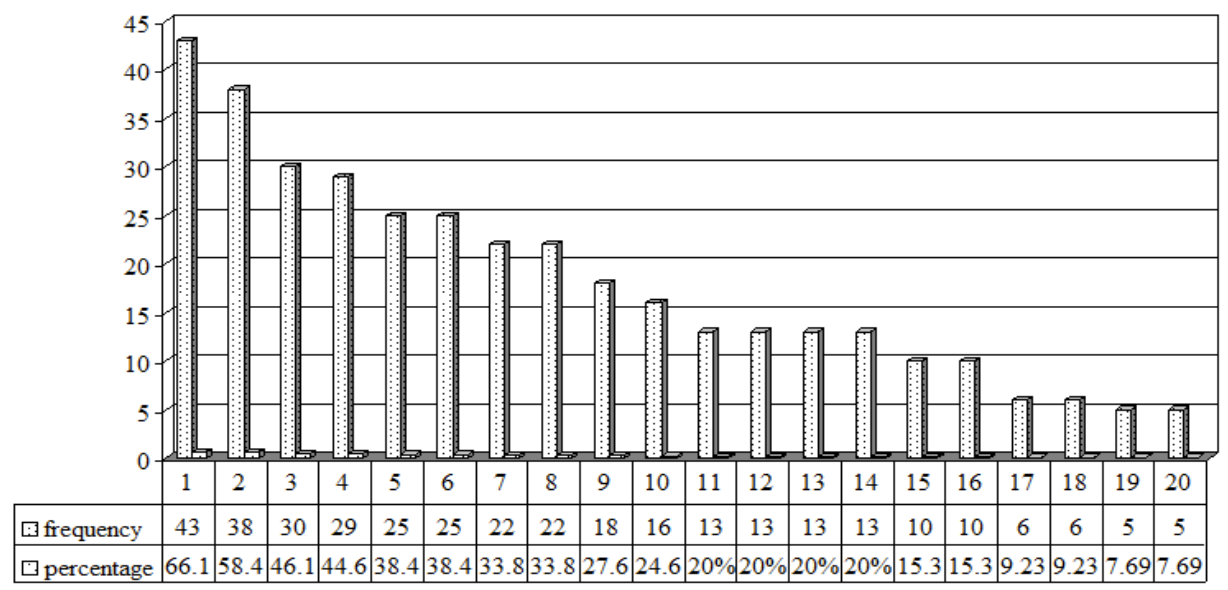

Fig. (7). Township high school sports teaching practice.

then cultivate modern youth morality and willpower, which is an important link in fostering qualified future successors that develop in all-around way in morality, intelligence, physique, aesthetics and labour.

Respectively carry out comparative analysis of rural and urban primary school, junior high school, senior high school physical education course teaching contents, results are as following: As primary school's physical education course, it should mainly work on fostering students' sports interests and developing students' basic activity capacity, teaching contents also should base on all kinds of activity skills and games, through comparison between towns and cities, it is clear frequency of event 1 , game, 2, walking and running, 3 , free-hand exercises in rural primary school sports practice course is bigger that is respectively $72.29 \%, 55.42 \%$ and $45.78 \%$. These proportions are obvious higher than that in cities. As junior high school physical education course, it should also mainly work on fostering students' sports interests and developing students' basic activity capacity, teaching contents also should base on all kinds of activity skills and games, but it needs to properly add some physical education professional knowledge to improve junior high school students' physical health, through comparison between towns and cities, it is clear frequency of event 1, walking and running, 2, leaping, 3, throwing in rural junior high school sports practice course is larger that is respectively $72.2 \%$, $73.8 \%$ and $66.6 \%$. The proportions are obvious more than city junior high school sports course's sports activity practice course, but strength quality and speed quality also corresponding increase while still has deficiency with regard to city. As senior high school physical education course, it should mainly work on fostering students' sports skills and developing students' activity capacity, teaching contents also should base on all kinds of activity skills and corresponding sports event to teach, so senior high school's physical education course contents mostly equip with sports specific events as basketball, football, volleyball and so on, through comparison between towns and cities, it is clear frequency of event 1, basketball, 2, walking and running, 3 , speed quality in rural senior high school sports practice course is larger that is respectively $66.1 \%, 58.4 \%$ and $46.1 \%$. The proportions are nearly the same as that in city.

\section{CONFLICT OF INTEREST}

The authors confirm that this article content has no conflict of interest.

\section{ACKNOWLEDGEMENTS}

Declared none.

\section{REFERENCES}

[1] C. Yang, and M.A. Ge-sheng, "An empirical study on community sports service residents' satisfaction index model," China. Sport Sci. Technol., vol. 45, no. 4, pp. 30-38, 2009.

[2] H. Ying, and X. Ming, "Theoretical and empirical study on evaluation mode of sports service satisfaction degree in city community," J. Wuhan Inst. Phys. Educ., vol. 41, no. 11, pp. 40-42, 2007.

[3] L. Bao, H. Shan-lian, X. Hai-xia, and G. Jian-hui, "Indices of the equality of essential public health services in China," China, J. Health Pol., vol. 2, no. 6, pp. 13-17, 2009.

[4] W. Guo-hong, and Z. Wen-hui, "Construction of the evaluation index system of city community sports: Taking Shanghai as an Example," J. Chengdu Phys. Educ. Inst., vol. 36, no. 2, pp. 20-30, 2010.

[5] Z. Da-chao, and L. Min, "Studies on evaluation index system of public sports facilities development level in China," China, Sport Sci., vol. 33, no. 4, pp. 3-23, 2013 